\title{
Optimal Control of Hybrid Photovoltaic-Thermometric Generator System Using GEPSO
}

\author{
Maryam Ejaz \\ Department of Automation, University of Science and Technology of China, Hefei, China \\ Email: maryam09@mail.ustc.edu.cn
}

How to cite this paper: Ejaz, M. (2022) Optimal Control of Hybrid PhotovoltaicThermometric Generator System Using GEPSO. Journal of Power and Energy Engineering, 10, 1-21.

https://doi.org/10.4236/jpee.2022.103001

Received: December 23, 2021

Accepted: March 5, 2022

Published: March 8, 2022

Copyright $\odot 2022$ by author(s) and Scientific Research Publishing Inc. This work is licensed under the Creative Commons Attribution International License (CC BY 4.0).

http://creativecommons.org/licenses/by/4.0/

\begin{abstract}
Recently the concern about energy consumption across the globe has become more severe due to global warming. One essential way to address this problem is to maximize the efficiency of existing renewable energy resources and effectively eliminate their power losses. The previous studies on energy harvesting of photovoltaic (PV) modules try to cope with this problem using gradient-based control techniques and pay little attention to the significant loss of solar energy in the form of waste heat. To reconcile these waste-heat problems, this paper investigates hybrid photovoltaic-thermoelectric generation (PV-TEG) systems. We implement the generalized particle swarm optimization (GEPSO) technique to maximize the power of PV systems under dynamic conditions by utilizing the waste heat to produce electricity through embedding the thermoelectric generator (TEG) with the PV module. The removal of waste heat increases the efficiency of PV systems and also adds significant electrical power. As a control method, the proposed GEPSO can maximize the output power. Simulations confirm that GEPSO outperforms some state-of-the-art methods, e.g., the perturb and observe (PO), cuckoo search (CS), incremental conductance (INC), and particle swarm optimization (PSO), in terms of accuracy and tracking speed.
\end{abstract}

\section{Keywords}

Thermoelectric Generator (TEG), PV System, Maximum Power Point

Tracking (MPPT), Photovoltaic (PV), Generalized Particle Swarm Optimization (GEPSO), Energy Harvesting

\section{Introduction}

In recent years, the excessive use of fossil fuels led to massive environmental 
pollution. Therefore, electricity generation from renewable energy sources has become a viable alternative due to its inexhaustible and environmental friendliness. Among renewable energy sources, solar energy has drawn great attention because of its advantages, such as cost parity, zero fuel cost, noise-free, inexhaustible and least maintenance. Generally, photovoltaic (PV) systems are implemented to harvest clean and green energy since energy is supplied by nature. However, the efficiency of PV cells primarily depends on specific environmental conditions, such as solar irradiation, temperature, and shading patterns. PV system has a significant drawback that it only converts a small portion of solar irradiation into energy other than that a large amount of available energy is wasted [1] in the form of heat. The heat energy absorption by the PV panels raises the nominal temperature of PV cells which decreases the energy conversion efficiency [2]. Consequently, reducing the life span of PV panels. To avoid heating of PV panels and extend their lifetime, thermoelectric generators (TEG) can be used that will act as a cooling agent and will reduce the temperature of PV cells [3]. In addition, TEGs are capable of converting this waste heat into electricity thus, providing a feasible solution to recover the extra heat energy and enhancing the system overall energy efficiency [2] [3] [4] [5]. TEGs do not contain any moving parts and being solid-state hardware that are highly durable. However, their applications are limited due to low energy conversion.

The TEG module contains a set of small several thermocouples [6] and is working via Seebeck effect principle [7]. A thermocouple is typically installed between two dielectric ceramics plates namely $p$ - and $n$-dopped semiconductors which lead to better thermal conductivity. One plate is interconnected to a heat source while the other acts as a heat-sink source. To attain the desired level of output voltage from TEG, thermocouples are often connected in series-parallel configurations for higher power rating operations. In past, thermoelectric (TE) materials have been utilized as temperature sensors, but significantly improved in the conversion efficiency of TEG systems due to the advancement in manufacturing technology thereby focusing on renewable electricity generation has enormously increased the scope of TEG applications. In many industrial operations, heat recovery processes, and automobiles engines, the TEG modules can able to convert the waste heat into electricity without affecting the normal process of flow [8] [9] [10]. The energy efficiency of TEG normally ranges from $5 \%$ to $10 \%$ [11]. An increase in thermal and electrical performance of the TEG system can improve the efficiency level. In the meantime, the hybrid photovoltaic cell and thermoelectric generator (PV-TEG) system is widely discussed in research since it has potential improved power conversion efficiency.

To use the waste heat from PV cells by using the thermoelectric modules has been a key-motivation for studying the hybrid PV-TEG systems. In literature, numerous studies revealed that a sufficient increase in energy has been achieved by embedding TEG modules in PV-TEG system. Hybrid PV-TEG systems can address the problem of broad spectrum solar radiations by utilizing the power generating ability of both PV and TEG modules. In view of this fact, researches 
are being made to make hybrid PV-TEG systems more durable and efficient. Several maximum power point tracking (MPPT) methods have been utilized to increase the power output of PV system and a dc-dc converter is used. The purpose of dc-dc converter is to control the reference voltage via modulated signal, as a result the system continuously track the maximum power point (MPP). The literature as documented in Refs. [12] [13] proposed the hybrid PV-TEG system instead of PV-based systems and obtained results showing the higher energy yield and eco-friendly environment. Further in Ref. [14], the implementation of PV-TEG systems for applications in water pumping systems substantiates that motor power output and the pump flow have increased. The hybrid PV-TEG presented in Ref. [15] confirmed that the energy output of hybrid PV-TEG systems has enhanced under various operating conditions. In addition, the control techniques to harvest the energy are playing a significant role in improving the energy conversion efficiency of hybrid PV-TEG systems. These techniques extract the optimal energy from the source and minimize power loss of the system through fixing the duty cycle of the dc-dc converter.

To date, many energy harvesting optimization algorithms [16] have been proposed in literature including incremental conductance (INC) [17], hill climbing (HC) [18], perturb and observe (P \& O) [19] that are widely accepted because of their low complexity. Moreover, a sliding mode control (SMC) [20], inflection voltages method [21], fractional open circuit voltage [22] [23], and mathematical-graphical approach [24] are used. In standard conditions, i.e., uniform irradiance and temperature, these techniques can harvest energy quite effectively at a good convergence speed. Despite these facts, the continual oscillation occurring around MPP appears in the aforementioned MPPT techniques. The oscillating nature at MPP causes a significant power loss in steady-state conditions. The gradient-based decision-making methods are insufficiently intelligent to deal with power loss caused by partial shading conditions (PSC) as documented in Ref. [25]. These undesired oscillations in voltage transients hinder the grid connectivity and reduce applications of PV-TEG in large-scale systems where time-sensitive stable control is a prime requirement under dynamic operating conditions.

To overcome the aforementioned problems, new metaheuristics algorithms are proposed in the literature. Among them, the bio-inspired optimization algorithms have been quite effective in dealing with MPP under nonlinear and stochastic issues [26]. Some typical bio-inspired approaches includes grey wolf optimization (GWO) [27], artificial bee colony (ABC) [28], genetic algorithm (GA) [29], Whale Optimization (WO) [30], cuckoo search (CS) [31], and particle swarm optimization (PSO) [32] so on. Although these approaches provide good results, however, still suffers from inefficient exploitation of solution in search space, procedural complexity, and their parameters need to be tuned properly. Further improvements have been suggested in the literature by implementing soft computing techniques such as memetic reinforcement learning [33], FLC-based 
techniques [34], and artificial neural network (ANN) [35]. Nevertheless, these approaches can effectively deal with the nonlinear properties of the $P V$-curves but needs substantial computing resources, and enormous amounts of data for training, which rely on the previous knowledge of the systems.

In this paper, a novel hybrid PV-TEG system is implemented and to deal with the shortcomings of aforementioned techniques, a generalized particle swarm optimization (GEPSO) [36] based MPPT approach is proposed to fill the research gap for integrated PV-TEG system. The main contribution of this paper is iterated as

- GEPSO provides a strong correlation among the exploration of the swarm particles and enhances the effectiveness and relative performance of the MPPT control.

- The efficient tracking of proposed technique reduces the power losses and increase the energy conversion efficiency.

- Results confirm the superiority of GEPSO in terms of tracking and settling time.

The structure of the paper is organized as follow: Section II explains the mathematical modeling of hybrid PV-TEG system and $\mathrm{dc} / \mathrm{dc}$ boost converter. Section III presents a description of proposed control MPPT technique GESPO. Section IV contains various case studies to validate the performance of the proposed method. Section V presents the summary of the work.

\section{Mathematical Modeling of PV and TEG Systems}

\subsection{Modeling of PV Cells}

Photovoltaic PV cell can be modeled as a semiconductor diode with a $p n$-junction in which electron-hole pairs are formed when the light strikes at the junction [18]. The current of an ideal PV cell is proportional to the amount of irradiation being received from the sun. A pictorial representation of the PV model using current source, diode, and resistor combinations is illustrated in Figure 1. The PV cell output current $I_{p h}$ is given by:

$$
I_{p v}=I_{p h}-I_{D}
$$

where $I_{D}$ is diode current.

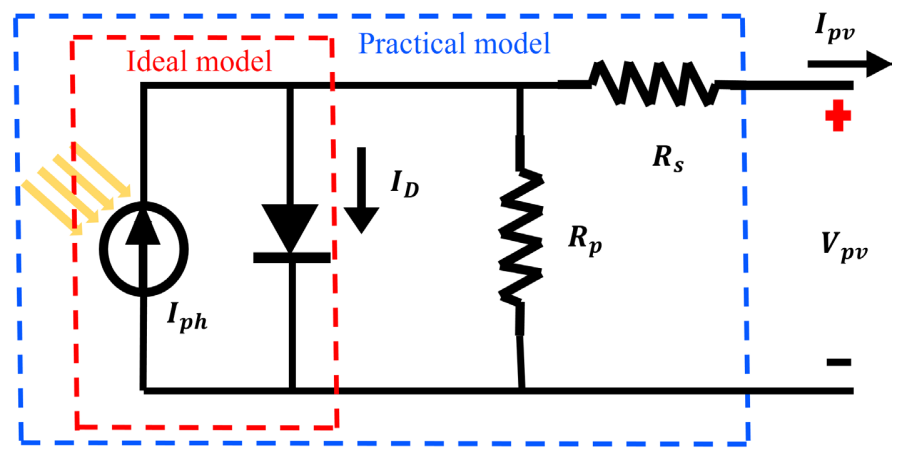

Figure 1. The simple equivalent electric circuit of PV cell. 
The PV module is formed by connecting multiple PV cells, linked in series to achieve necessary voltage and connected parallel to get the desired level output current. The current-voltage relation for PV cell can be expressed as:

$$
I_{p v}=N_{p} I_{p h}-N_{p} I_{s a t}\left[\exp \left(\frac{q}{k T n} \frac{V_{p v}}{N_{s}}\right)-1\right]
$$

where $V_{p r} q, I_{s a t}, k, T, N_{p}, N_{s}$ and $n$ represent the output voltage, electron charge, reverse saturation current, Boltzmann constant, temperature of PV cells, number series-parallel connected PV cells, and diode ideality factor, respectively. The efficiency of PV module can be calculated using Equation (3) as:

$$
\eta_{P V}=\frac{P_{p v}}{G \times \mathcal{A}_{P}}
$$

where $\mathcal{A}_{P}$ is cross-section area in $\mathrm{m}^{2}$ and $G$ is the irradiation in $\mathrm{W} \cdot \mathrm{m}^{-2}$ of the $\mathrm{PV}$ panel.

The output of PV system changes with respect to variations in atmospheric conditions/environmental inputs such as irradiance and temprature. The characteristic $I$ - $V$ curve is shown in Figure 2(a) while $P$ - $V$ curve in Figure 2(b) under varying irradiation with a constant temperature. Irradiation change only affects the current of PV module while keeping the voltage almost invariable.

Figure 3(a) and Figure 3(b) highlight the trend of $I$ - $V$ and $P$ - $V$ characteristics curves of the PV module at different temperature values under uniform irradiation conditions.

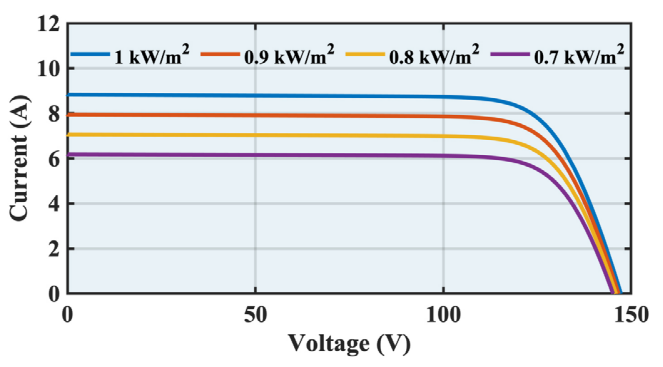

(a)

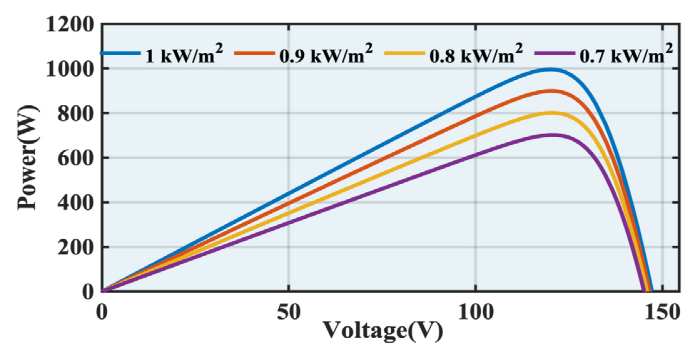

(b)

Figure 2. The distributions of characteristic curves under various irradiation conditions (a) $I-V$ curve (b) $P$ - $V$ curve.

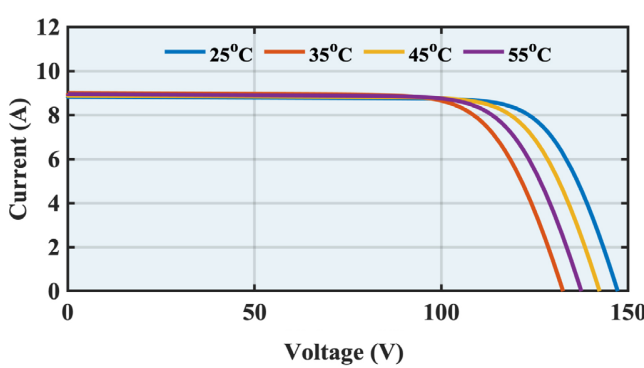

(a)

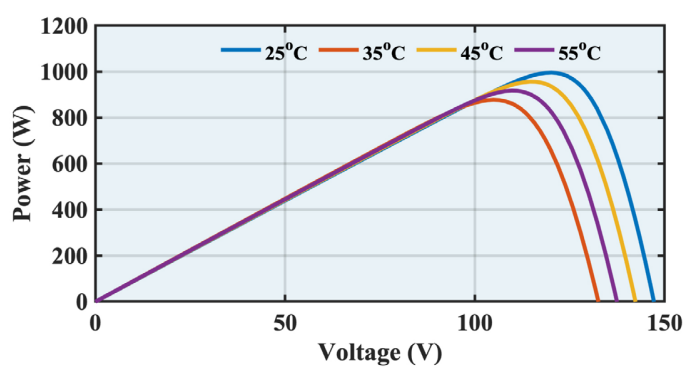

(b)

Figure 3. The distributions of characteristic curve under various temperature conditions (a) $I-V$ curve (b) $P$ - $V$ curve. 


\subsection{Modeling of Thermoelectric Generator (TEG)}

Thermoelectric generator TEG is typically built by connecting thermometric solid-state devices in series [8]. The equivalent electrical circuit is shown in Figure 4. The temperature difference across two ends of junctions produces an electromotive force so-called the Seebeck effect. The induced voltage due to Seebeck effect is expressed as follows:

$$
E_{T E G}=\kappa \cdot\left(T_{H}-T_{C}\right)=\kappa \cdot \Delta T
$$

where $T_{H}, T_{C}$ represents the hot- and cold-side surfaces temperature, and $\kappa$ represents the corresponding Seebeck coefficient. The Equation (5) can be used to calculate the Seebeck coefficient as:

$$
\kappa=\mathcal{N}_{t h} \cdot\left(\theta_{p}-\theta_{n}\right)
$$

where $\mathcal{N}_{t h}$ is the number of thermocouples, $\theta_{p}, \theta_{n}$ are the Seebeck coefficients. The output current, voltage and power of TEG are computed as:

$$
\begin{gathered}
V_{T E G}=R_{L} \times\left(\frac{\left(\theta_{p}-\theta_{n}\right) \times\left(T_{H}-T_{C}\right)}{\left(R_{L}-R_{\text {int }}\right)}\right) \times \mathcal{N}_{\text {th }} \\
I_{T E G}=\frac{\left(\theta_{p}-\theta_{n}\right) \times\left(T_{H}-T_{C}\right)}{\left(R_{L}+R_{i n t}\right)} \\
P_{T E G}=R_{L} \times\left(\frac{\left(\theta_{p}-\theta_{n}\right)^{2} \times\left(T_{H}-T_{C}\right)^{2}}{\left(R_{L}-R_{\text {int }}\right)^{2}}\right) \times \mathcal{N}_{t h}
\end{gathered}
$$

where $R_{L}, R_{\text {int }}$ are the applied load and internal resistance of TEG system. The $R_{\text {int }}$ is determined by:

$$
R_{\text {int }}=\left(\frac{L}{\beta A_{t}}+\frac{2 L_{C}}{\sigma_{C} A_{C}}\right)
$$

where $\sigma_{C}$ is the copper strip electrical conductivity, $A_{t}$ is the cross-sectional area of thermometric, $A_{C}$ is the copper strip cross-sectional area, $L$ is thermocouple length, $L_{C}$ is the copper strip length, and $\beta$ is the electrical conductive of thermocouple material, respectively.

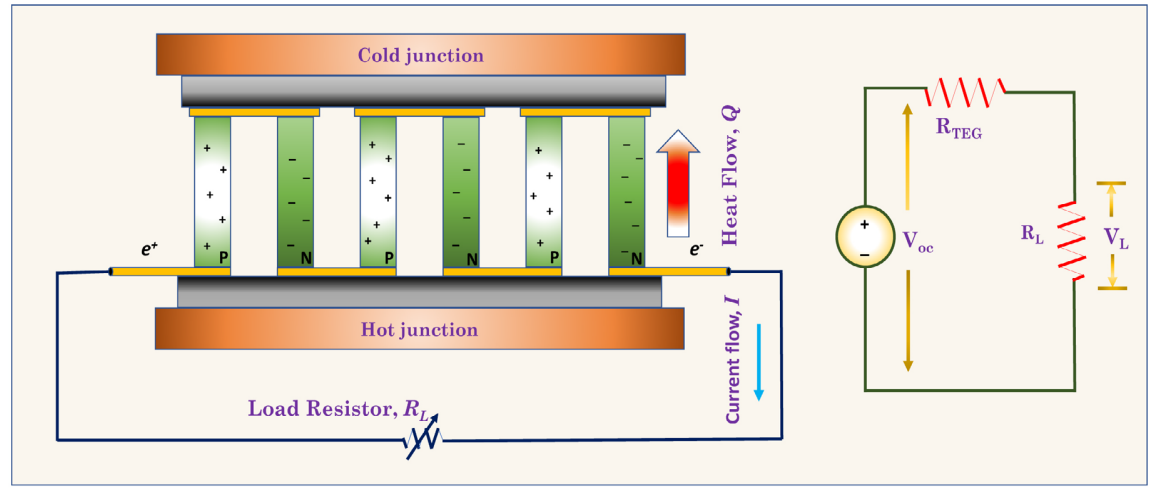

Figure 4. Physical overview and equivalent electrical circuit of TEG. 
The TEG gathers heat flux on the hot-side and emits on the cold-side. In addition to Seebeck effect $\kappa$ during the energy conversion, the Thomson and Peltier effects are also induced [8]. Notably, when load is applied the electric current drives through across the junctions of the material. The influence of Thomson effect on TEG module is so far neglected due to its minimal impact on the resistive load $R_{L}$. The energy equation for the TEG module is given by [1]:

$$
Q_{T E G}=q_{H}-q_{C}
$$

The variables in the above equation are defined as;

$q_{H}=\kappa I_{T E G} T_{H}-\frac{1}{2 \beta} I_{T E G}^{2}-\lambda_{t} \cdot\left(T_{H}-T_{C}\right)$ and $q_{C}=\kappa I_{T E G} T_{C}+\frac{1}{2 \beta} I_{T E G}^{2}+\lambda_{t} \cdot\left(T_{H}-T_{C}\right)$ which represents the energy at hot- and cold-sides of TEG, where $\lambda_{t}$ is the thermal conductance, $\kappa I_{T E G} T_{H}$ and $\kappa I_{T E G} T_{C}$ are the heat-flux at across its two ends, respectively. Hence, TEG model is designed using electrical and thermal properties of thermocouple TE materials.

\subsection{Modeling of Hybrid PV-TEG Generator}

The hybrid photovoltaic-thermometric generator PV-TEG power module [12] is designed to change the maximum solar irradiation into electricity. PV cells typically employ a little amount of incoming solar irradiation to create electricity while converting a substantial amount of solar irradiation into waste heat. Thus, the temperature of PV cells increases, which leads to a degradation of the energy efficiency of the PV system. Figure 5 depicts a typical hybrid PV-TEG module layout. The proposed system consists of TEG with heat-sink that makes use of waste heat energy from PV system to increase power generation and decrease the temperature of PV cells. PV array serves as a heat source for the TEG and heat sink is placed on the TEG cold-side. The heat sink ensures the sufficient temperature differential across its two terminals. Furthermore, heat sink reduces the ambient temperature of PV cell, as a result improving energy conversion efficiency of the PV-TEG system. The energy conversion efficiency of hybrid PV-TEG system is formulated as:

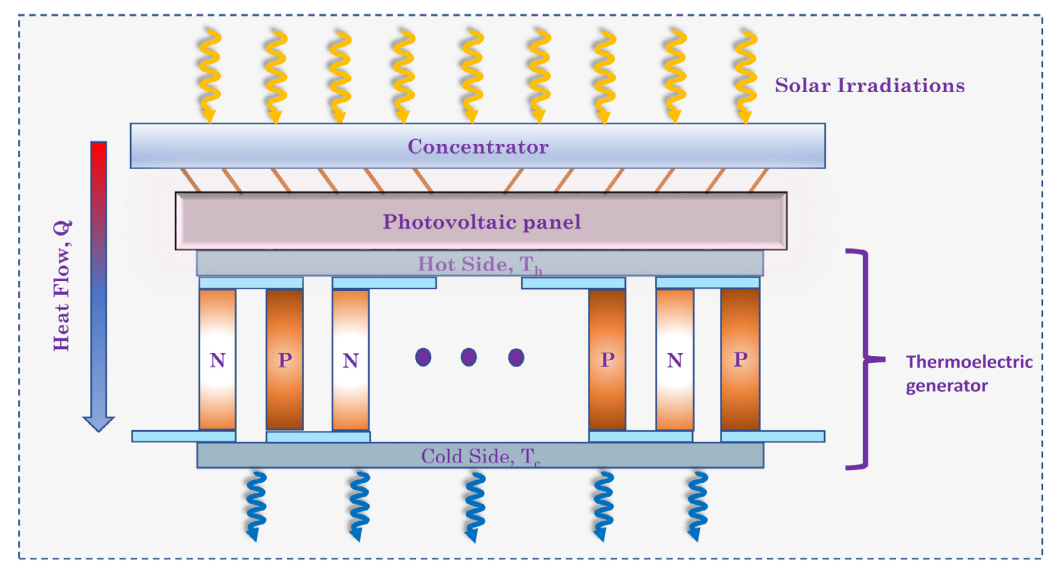

Figure 5. Complete overview of hybrid PV-TEG system. 


$$
\eta_{P V-T E G}=\frac{P_{p v}+P_{T E G}}{G \times \mathcal{A}_{P}}
$$

The PV arrays and TEG can be connected parallel or serially for the hybrid system; however, extra power electronic switches are required for parallel connections, increasing power losses. On the other hand, the serial connection of PV and TEG has fewer power switches and less power loss. The energy efficiency of the PV power system mainly depends on the ratio of energy generated to the quantity of solar input power per unit area while TEG's depends on the amount of input heat energy at the hot end to the amount of heat energy emitted at the cold end. In this hybrid model, the PV temperature act as TEG input and electrical energy is produced at its output.

\subsection{Boost Converter}

Boost converter adequate provided voltage between PV array and load resistance $R_{L}$ [37]. It has ability to control signal via duty cycle which allows the PV array to operate at optimal point. The characteristic equations for the input-output capacitance, output voltage, inductor, and other electrical parameters are presented from Equation (12) to Equation (16).

$$
\begin{gathered}
V_{o}=\frac{V_{i-p v}}{1-d_{b}} \\
d_{b}=\frac{T_{o n}}{T_{\text {switching }}} \\
C_{i}=\frac{d_{b}}{8 \times f^{2} \times L \times 0.01} \\
L=\frac{d_{b} \times\left(1-d_{b}\right)^{2} \times R_{L}}{2 \times f} \\
C_{o}=\frac{d_{b}}{0.02 \times f \times R_{L}}
\end{gathered}
$$

where $d_{b}$ is the duty cycle of $\mathrm{dc} / \mathrm{dc}$ boost converter, $V_{i}, V_{o}$ are the input and output voltage, $C_{i}$ is input and $C_{o}$ is output capacitor and $L$ is the inductor to reduce the ripple current.

\section{Proposed GEPSO Technique}

\subsection{PSO MPPT Algorithm}

Kennedy and Eberhart first proposed particle swarm optimization PSO based MPPT approach in 1995 which utilizes the idea of swarms like fish and birds. PSO is built upon a collection of group members termed as particles which represent solutions and coordinate with each other using social interactions and experience models. The particles begin exploring for food/shelter randomly in a search area. Once the goal is achieved, the information is conveyed to other searching members. After being transitioned into the optimization process, this 
simple PSO model is able to solve complex optimization problems with less computation complexity than classical control techniques. In PSO, there is a main nesting loop that terminates whenever a particular goal, limit, or minimal threshold is achieved. Particularly, Equation (17) is used to update the location of each particle at each function iteration and the particle flies to a different position which is determined by a fitness function that analyzes each solution quality. The velocity of the particles is determined by Equation (18) as:

$$
\begin{gathered}
\operatorname{Prtpos}_{j}^{i}=\operatorname{Prtpos}_{j}^{i-1}+\text { Prtvel }_{j}^{i} \quad \forall i \in N_{i t e r}, \forall j \in N_{p} \\
\text { Prtvel }_{j}^{i}= \\
w \text { Prtvel }_{j}^{i-1}+c_{1} r_{1}^{i}\left(\text { pbest }_{j}^{i-1}-\text { prtpos }_{j}^{i-1}\right) \\
+c_{2} r_{2}^{i}\left(\text { gbest }^{i-1}-\text { prtpos }_{j}^{i-1}\right) \quad \forall i \in N_{i t e r}, \forall j \in N_{p}
\end{gathered}
$$

where pbest $_{j}$ represents the best fitness value of particle $j$, gbest represents the best fitness value of the whole swarm, $c_{1}$ and $c_{2}$ are the constriction factor (for limiting the velocity of the particles), $w$ denotes the inertia weights (for regulating the global search), and $r_{1}$ and $r_{2}$ represent random numbers.

\subsection{GEPSO MPPT Algorithm}

This paper employs energy harvesting algorithm so-called generalized particle swarm optimization GEPSO [36] that enhances the original PSO performance and its effectiveness for MPPT control problem. This approach uses a dynamic weight adjustment mechanism to enhance the updating formula for particle velocity. In Equation (17), the GEPSO position updating equation stays the same as that of the original PSO while its velocity update equation is altered by the addition of two new terms as:

$$
\begin{aligned}
\text { Prtvel }_{j}^{i}= & \psi\left[w_{1}^{i} \text { Prtvel }_{j}^{i-1}+w_{2} c_{1} r_{1}^{i}\left(\text { pbest }_{j}^{i-1}-\text { prtpos }_{j}^{i-1}\right)\right. \\
& +w_{3} \alpha_{1} c_{2} r_{2}^{i}\left(\text { gbest }^{i-1}-\text { prtpos }_{j}^{i-1}\right)+w_{4} \alpha_{2} c_{3} r_{3}^{i}\left(\text { pbest }_{\text {rand }}^{i-1}-\text { prtpos }_{j}^{i-1}\right) \\
& \left.+w_{5} \alpha_{3} c_{4} r_{4}^{i} \text { Prtvel }_{\text {rand }}\right] \quad \forall i \in N_{\text {iter }}, \forall j \in N_{p}
\end{aligned}
$$

where $\psi$ represents the constriction parameter and can be determined by:

$$
\psi=\frac{2}{\left|2-\left(c_{2}+c_{3}\right)^{2}-5\left(c_{2}+c_{3}\right)\right|}
$$

and $w_{1}$ in Equation (19) represents the inertia weight which is dynamically updated in each function iteration as follows:

$$
w_{1}^{i}=\min \left\{w_{\min }, w_{1}^{i-1}+\left[\frac{w_{\max }-w_{\min }}{\text { iter }_{\max }} i\left(f\left(\text { gbest }^{i-1}\right)-f\left(\text { gbest }^{i-2}\right)\right)\right]\right\} \forall i \in N_{\text {iter }}
$$

Throughout the searching process, $w_{1}^{i}$ will always be equal to or greater than a minimal inertia value. As the swarm's best fitness function improves compared to its previous function iteration, $w_{1}^{i}$ also increases proportionally. Thus, with the improvement of gbest, the effect of the current velocity direction increases, leading to deeper exploitation of the existing solution. On contrary to that $w_{1}^{i}$ 
decreases whenever the worst value of the fitness function appear compared to the previous function iteration, which prevents the particles from moving along their past direction and leads to more exploration of the search space. Figure 6 shows the updating of particle's positions in two consecutive function iterations of the GEPSO algorithm [36]. The position and velocity of the particle are initialized by Equation (22) and Equation (23) as:

$$
\begin{aligned}
& \operatorname{Prtpos}_{j}^{0}\left(x_{k}\right)=x_{k, \text { min }}+\operatorname{rand}_{k, \text { max }} \quad \forall j \in N_{p}, k \in N_{k} \\
& \operatorname{Prtvel}_{j}^{0}\left(x_{k}\right)=\operatorname{Prtpos}_{j}^{0}\left(x_{k}\right)+\gamma_{k} \quad \forall j \in N_{p}, k \in N_{k}
\end{aligned}
$$

The third term in Equation (19) increases the interrelation between particles and ensures the swarm more swiftly converge towards optimum solutions. The impact of random velocities, leads to improve swarm exploration in many unexplored regions of the search space. The parameters in the first three terms in Equation (19) significantly improve the algorithm's performance.

In general terms for the hybrid PV-TEG system, the fitness function is modeled as the output power. The corresponding search for optimum control value can be defined as $d_{k}$ in the possible set of solutions $D$ using the fitness function $\left(P\left(d_{k}\right)=V_{k} \cdot I_{k}\right)$ such that $\forall d \in U \subseteq D: P(d) \geq P\left(d_{0}\right)$. For $U=D, d$ is called a global optimum, otherwise it is called a local optimum of $P(d)$ in $D$. The flowchart and pseudo-code of the overall process of GEPSO are presented in Figure 7 and Figure 8, respectively.

\section{Results and Discussion}

The performance testing setup consists of four serially connected PV modules with a boost converter that provides an interface between PV-TEG output and load resistance. MPPT controller generates the optimum duty cycle depending upon the sensors data. The results of generalized particle swarm optimization

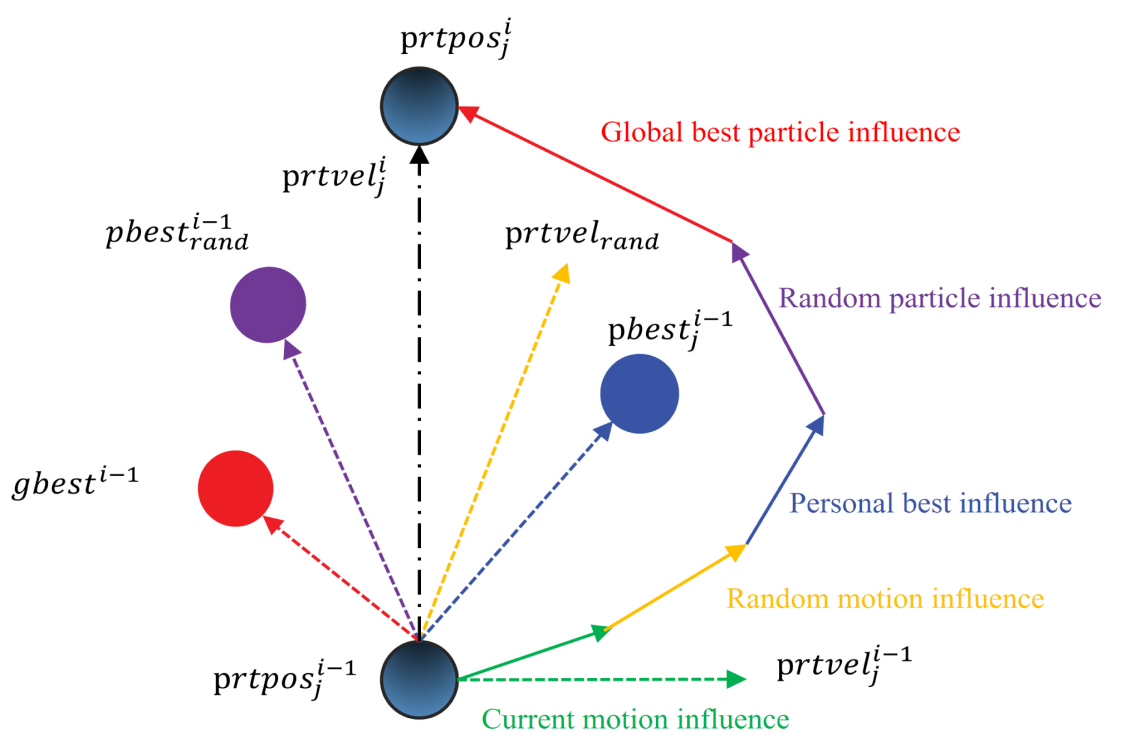

Figure 6. Velocity update mechanism in GEPSO. 


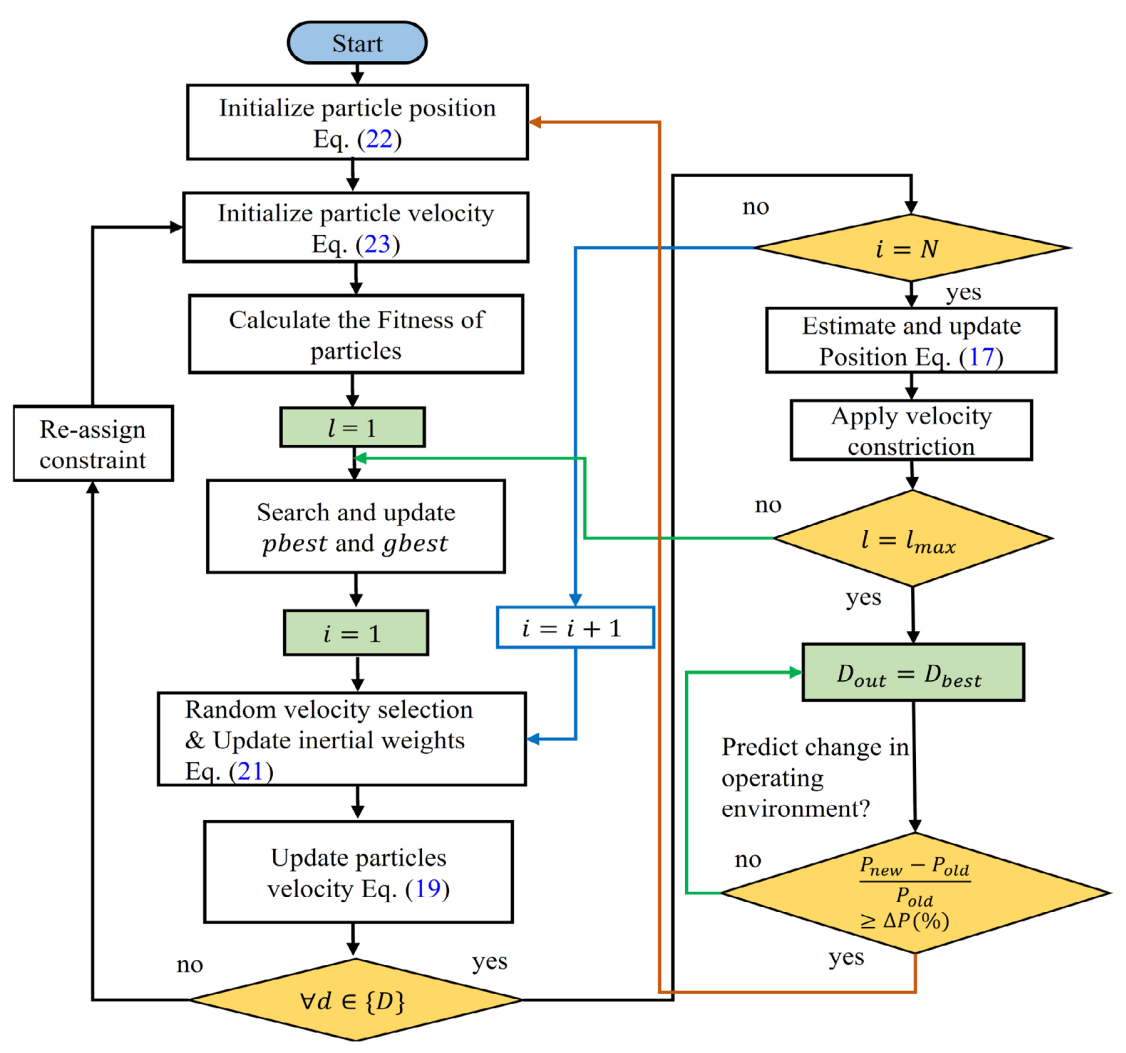

Figure 7. Flowchart of GEPSO.

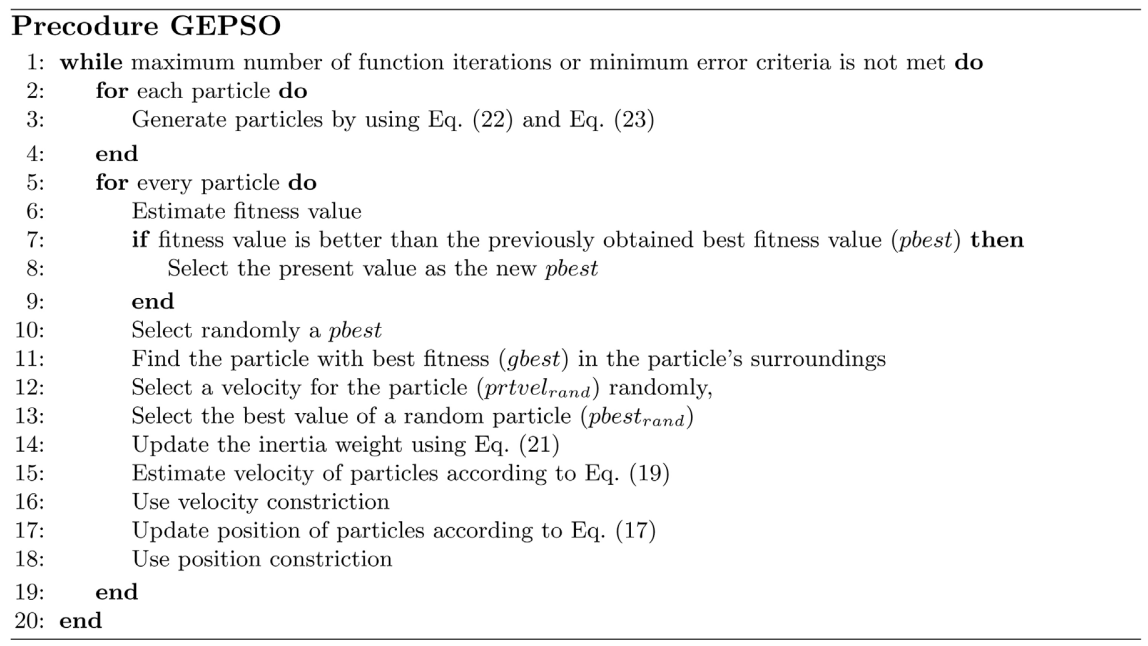

Figure 8. Pseudo-code of GEPSO.

(GEPSO) are compared with other well-known methods, such as, the cuckoo search (CS), the incremental conductance (INC), particle swarm optimization (PSO), and the perturb and observe ( $\mathrm{P} \& \mathrm{O})$, respectively. The simulation results of GEPSO on a hybrid PV-TEG system are explained in Case 5 and Case 6. The standard hybrid PV-TEG model with GEPSO based MPPT controller is illustrated in Figure 9. The specifications of components used for matlab/simulink are listed in Table 1. 


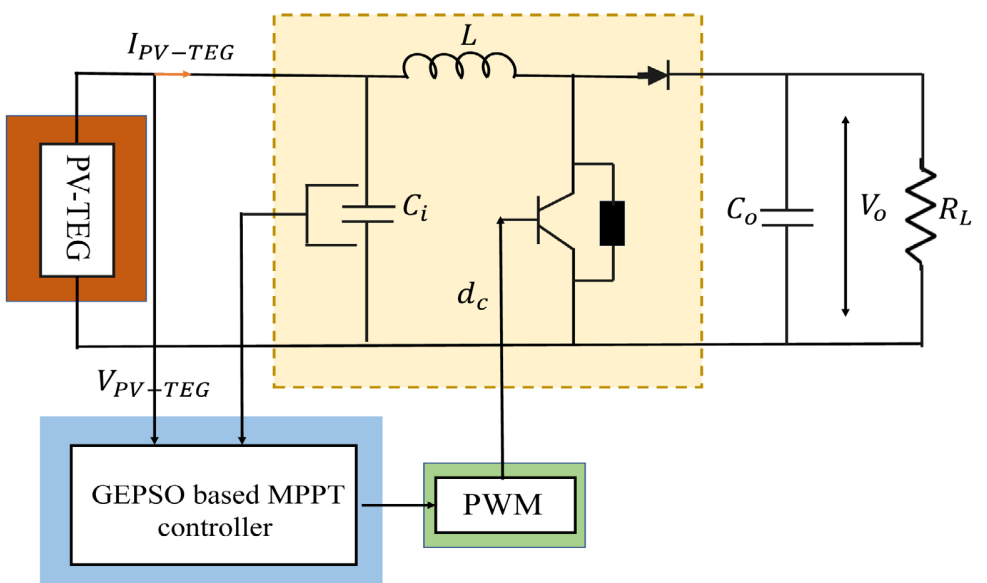

Figure 9. A schematic diagram of hybrid PV-TEG system with MPPT control.

Table 1. Specifications of PV system and dc boost converter.

\begin{tabular}{cc}
\hline Component & Value \\
\hline PV panel & $249 \mathrm{~W}$ \\
Input capacitor & $10 \mu \mathrm{F}$ \\
Load resistance & $53 \Omega$ \\
Output capacitor & $0.47 \mathrm{mF}$ \\
Inductor & $1.14 \mathrm{mH}$ \\
Switching frequency & $50 \mathrm{kHz}$ \\
\hline
\end{tabular}

\subsection{Case 1: Varying Temperature with Constant Irradiance}

The GEPSO is tested under varying temperature to verify its effectiveness. The temperature gradient is summarised in Figure 10(a) showing gradual change in the operating conditions that enforce the MPPT control to actively track the GM in dynamic state. Figure 11 confirms that GEPSO can efficiently track MPP under a drastic change in temperature of the environment. The average power attained by GEPSO is $916.6 \mathrm{~W}, \mathrm{CS}$ is $904.2 \mathrm{~W}$, INC is $902 \mathrm{~W}$, PSO is $882.4 \mathrm{~W}$ and $\mathrm{P} \& \mathrm{O} 885.2 \mathrm{~W}$. Time interval ranging from 0 to $1 \mathrm{~s}$, the CS locates MPP at $0.32 \mathrm{~s}$ and settles at $0.77 \mathrm{~s}$, while PSO continuously shows the oscillations. INC slowly tracks the MPP, and at $0.9 \mathrm{~s}$, locates the MPP. P \& O locates the MPP at $0.10 \mathrm{~s}$, but involves oscillations constantly during tracking. At the same time, the proposed GEPSO algorithm locates MPP within $0.47 \mathrm{~s}$ and starts tracking.

With the change in temperature from $1.5 \mathrm{~s}$ to $2.5 \mathrm{~s}$, GEPSO and CS continuously track the MPPT without losing the tracking direction while PSO generates random fluctuations. $\mathrm{P} \& \mathrm{O}$ and INC continue tracking with fixed magnitude oscillations causing power loss proportional to the step size of control variable. PSO tracks MPPT but involves small oscillations while P \& O involves continuously oscillations during tracking when the temperature changes. 


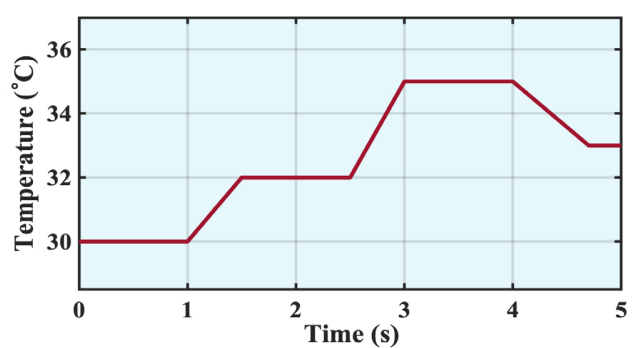

(a)

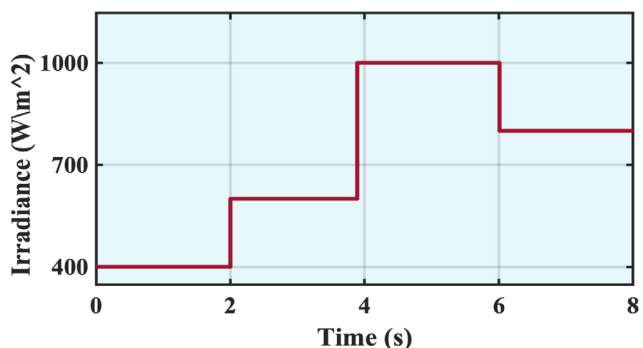

(b)

Figure 10. Operating conditions of (a) Case 3: temperature change with time (b) Case 4: step-change in irradiance with time.

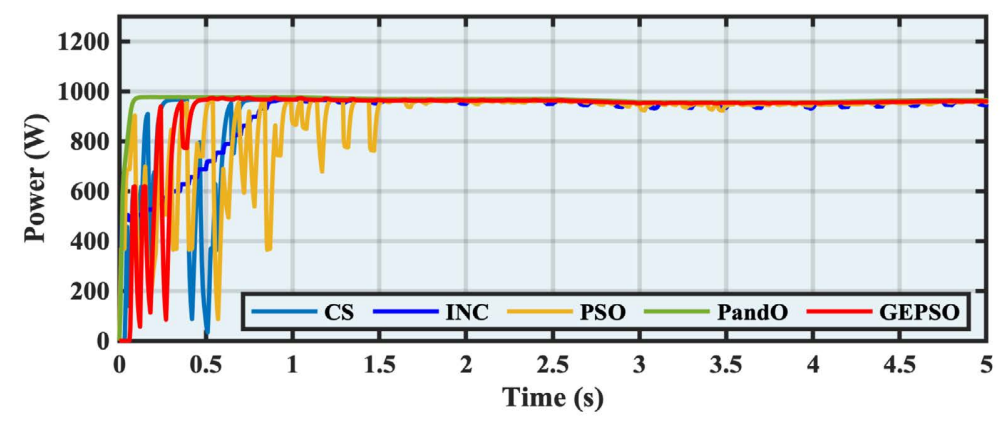

Figure 11. Power comparison in Case 1.

\subsection{Case 2: Step-Change in Irradiance with Constant Temperature}

Figure 10(b) shows the curve for a step-change in irradiance, which occurs due to the passing of cloud over PV modules rapidly. Under such situations, the algorithm's performance is evaluated for various levels of irradiance applied to the PV array. The average power obtained by GEPSO is $693.9 \mathrm{~W}$, CS is $651 \mathrm{~W}$, INC is $657.1 \mathrm{~W}$, PSO is $653.8 \mathrm{~W}$, and P \& O is $632 \mathrm{~W}$. The overall efficiency of GEPSO is $99.1 \%$, CS is $93.1 \%$, INC $93.9 \%$, PSO is $93.4 \%$, and P \& O is $90.3 \%$. The settling time calculated for GEPSO, CS, INC, PSO and P \& O is $0.29 \mathrm{~s}, 1.02$ s, $0.4 \mathrm{~s}, 1.2 \mathrm{~s}$ and $0.11 \mathrm{~s}$, respectively. P \& O and INC do not converge at MPP due to the oscillations during tracking. With step-change in irradiance, GEPSO reaches new MPP faster than any other algorithm. The settling time of GEPSO is faster than any other technique for every step-change in irradiance, as observed from Figure 12. The comparison result of duty cycle of implemented MPPT techniques is shown in Figure 13.

\subsection{Case 3: Partial Shading}

Case 3 deals with partial shading conditions PSC for which irradiation pattern is shown in Table 2 and the global maxima (GM) lies on PV curve with power and voltage values of $607.5 \mathrm{~W}$ at $93.9 \mathrm{~V}$. The PV curve under partial shading is shown in Figure 14(a). The comparison of power and duty cycle under partial shading is shown in Figure 15(a) and Figure 15(b). Some MPPT approaches include selecting random particles to break the local maxima (LM) trap. PSO and CS involve quite randomness during the searching process. In these 


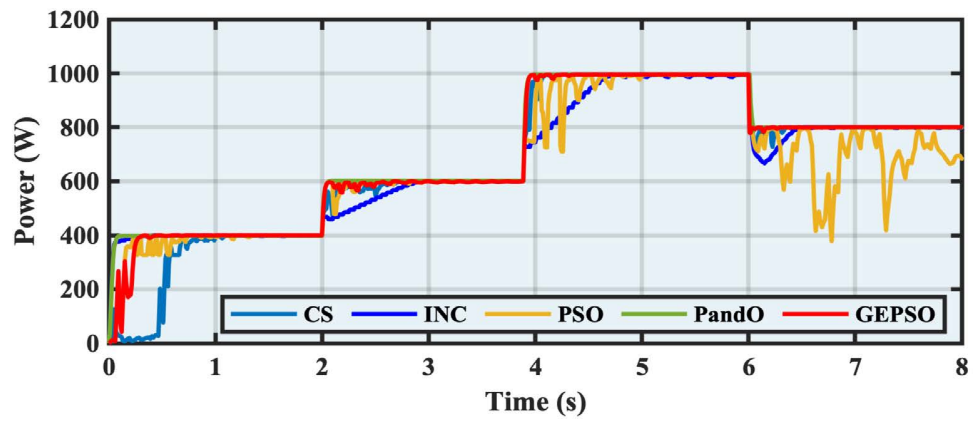

Figure 12. Power comparison in Case 2.

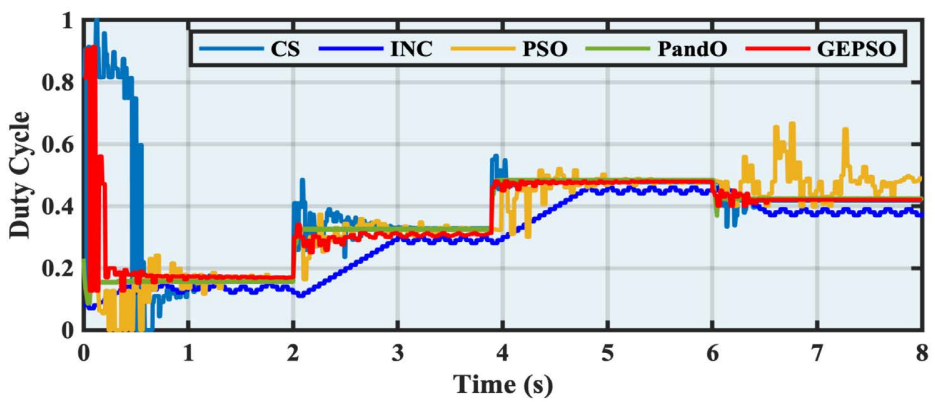

Figure 13. Duty cycle comparison in Case 2.

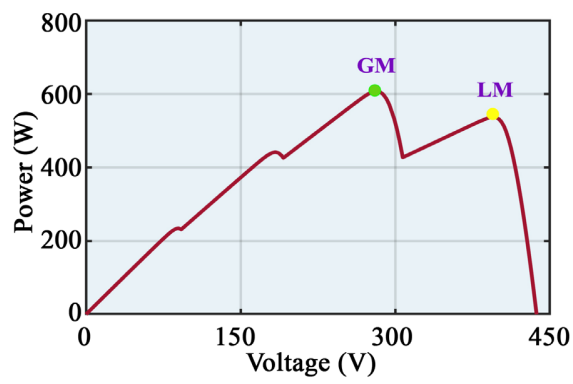

(a)

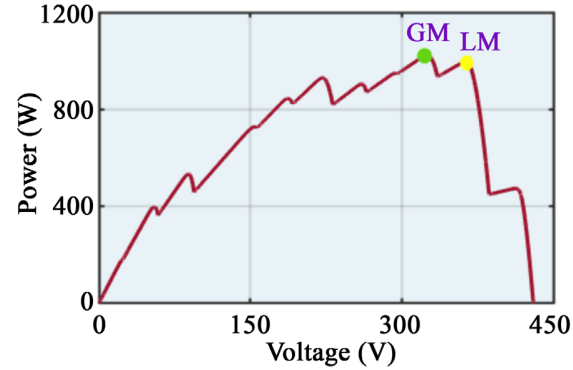

(b)

Figure 14. Partial shading case studies (a) Case 3: partial shading (b) Case 4: complex partial shading.

Table 2. Irradiance pattern for Case 3 and Case 4.

\begin{tabular}{cccccc}
\hline Case study & \multicolumn{3}{c}{ Irradiance $\left(\mathrm{kW} \cdot \mathrm{m}^{-2}\right)$} & & $P_{\max }(\mathrm{W})$ \\
\hline Case 3: Partial shading & 500 & 800 & 1000 & 900 & 607 \\
& $\mathrm{PV}_{1}: 515$ & $\mathrm{PV}_{2}: 395$ & $\mathrm{PV}_{3}: 745$ & $\mathrm{PV}_{4}: 915$ & $\ldots$ \\
Case 4: Complex partial & $\mathrm{PV}_{5}: 555$ & $\mathrm{PV}_{6}: 425$ & $\mathrm{PV}_{7}: 985$ & $\mathrm{PV}_{8}: 335$ & 1023 \\
shading & $\mathrm{PV}_{9}: 385$ & $\mathrm{PV}_{10}: 140$ & $\mathrm{PV}_{11}: 585$ & $\mathrm{PV}_{12}: 585$ & $\ldots$ \\
\hline
\end{tabular}

techniques, step size for the duty cycle is increased randomly, resulting in unwanted oscillations.

A GEPSO algorithm is used to reduce the fluctuations during GM-power point (GMPP) tracking significantly. Oscillations are minimized, which decreases the power dissipation and increases the efficiency. P \& O, PSO and INC are 


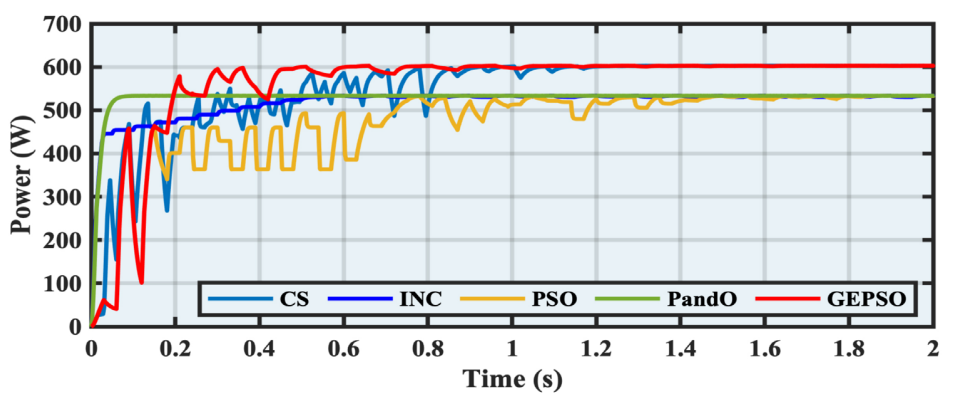

(a)

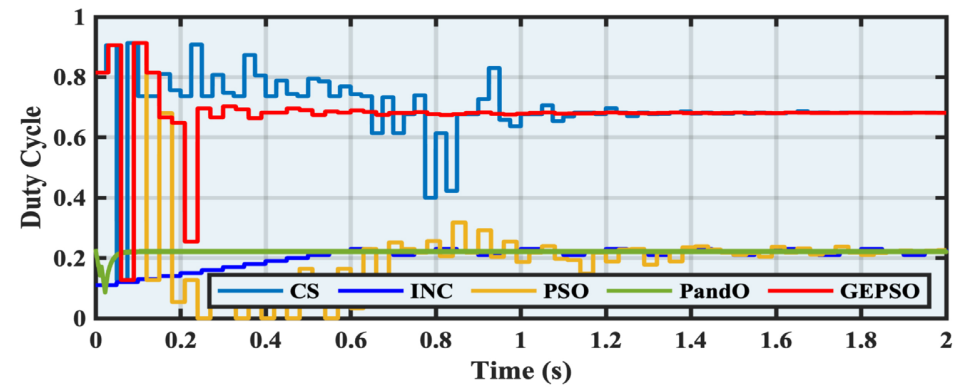

(b)

Figure 15. (a) Power comparison in Case 3 (b) Duty cycle comparison in Case 3.

unable to reach GM and are caught in LM at $534 \mathrm{~W}$. Thus, their efficiency is limited to the power at LM. CS locates GM within $0.77 \mathrm{~s}$ whereas GEPSO locates GM within $0.29 \mathrm{~s}$. The settling time of GEPSO is $1.03 \mathrm{~s}$, whereas that of CS is $1.18 \mathrm{~s}$. In terms of the tracking power under partial shading, GEPSO shows quite prominent and efficient results. The maximum power attained by GEPSO is 603 $\mathrm{W}, \mathrm{CS}$ is $603 \mathrm{~W}$, INC is $534 \mathrm{~W}$, PSO is $533.9 \mathrm{~W}$, and P \& O is $533.6 \mathrm{~W}$. The overall efficiency of GEPSO is $99.3 \%$, CS is $99.3 \%$, INC $87.97 \%$, PSO is $87.95 \%$ and $\mathrm{P} \& \mathrm{O}$ is $87.8 \%$. GEPSO shows $100 \%$ success rate in GM detection.

\subsection{Case 4: Complex Partial Shading}

This type of shading is caused by extensive partial shading of a significantly large number of series-connected PV modules. In this situation, several peaks are generated, which are closely related. In complex partial shading condition, the PV curve is shown in Figure 14(b) where 12 PV modules are serially attached and applied irradiance pattern is listed in Table 2. The performance of GEPSO is examined by comparing obtained results with CS, PSO, P \& O and INC in Figure 16(a). The duty cycle comparison of implemented techniques is shown by Figure 16(b). The maximum power at GM is $1023 \mathrm{~W}$. P \& O and INC were unable to reach GMPP and stuck around the LM of $997 \mathrm{~W}$. PSO is able to track the GMPP, but involves a lot of oscillations which result in power loss.

The settling time of PSO is $1.99 \mathrm{~s}$. The CS reaches the GMPP within a tracking time of $0.85 \mathrm{~s}$, whereas GEPSO tracks the MPPT within $0.57 \mathrm{~s}$. The overall efficiency of GEPSO is $99.9 \%$, CS is $99.8 \%$, INC $96.8 \%$, PSO is $98.8 \%$, and P \& O is 96.5\%. Figure 17 shows the proposed GEPSO algorithm can track the GMPP with a fewer number of iterations and in less time than others. 


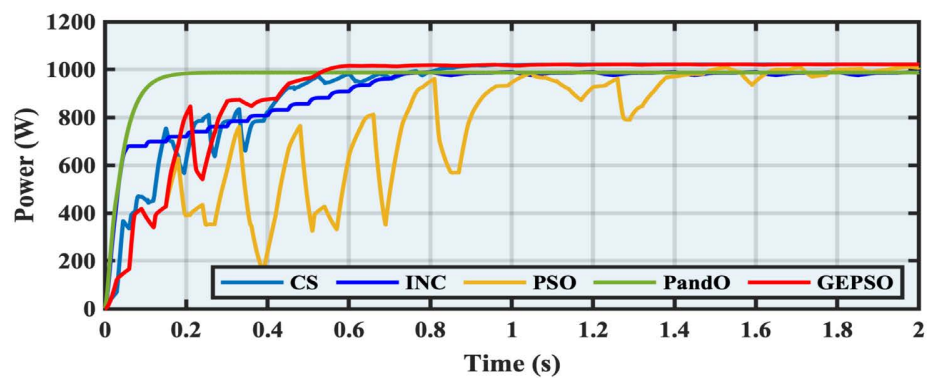

(a)

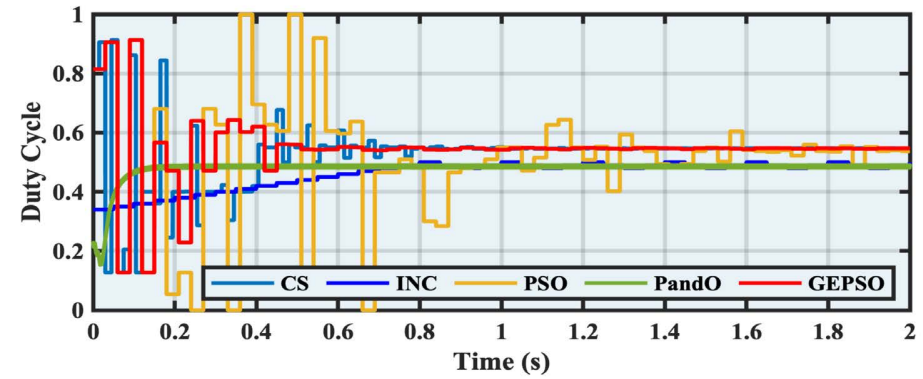

(b)

Figure 16. (a) Power comparison in Case 4. (b) Duty cycle comparison in Case 4.

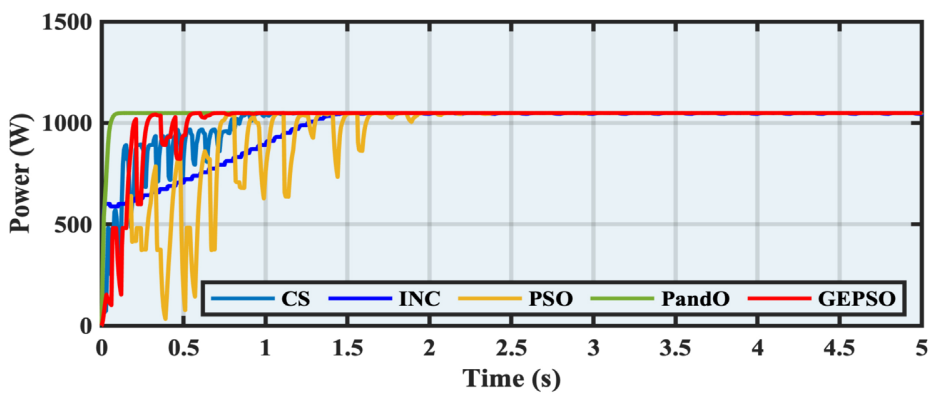

(a)

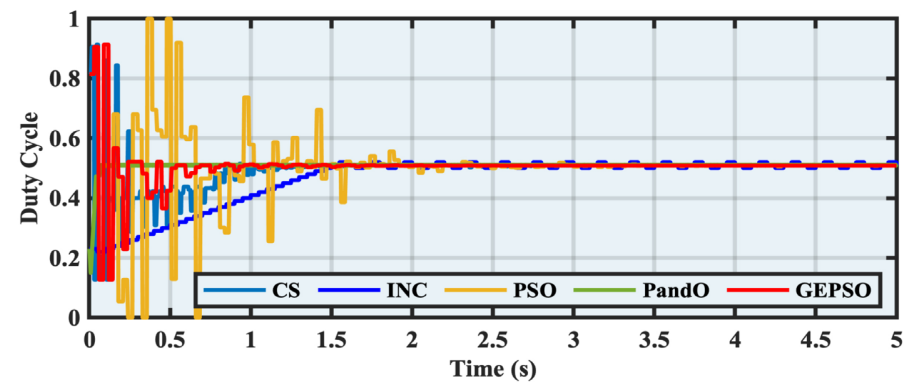

(b)

Figure 17. (a) Power comparison in Case 5. (b) Duty cycle comparison in Case 5.

\subsection{Case 5: Hybrid PV-TEG System}

In the proposed hybrid PV-TEG energy module, the maximum power extraction ability of MPPT methods is examined under STC. Figure 17(a) shows the power output from the system utilizing GEPSO, CS, PSO, P \& O and INC MPPT algorithms under STC. Figure 17(b) shows the duty cycle of GEPSO-based MPPT technique implemented on a hybrid PV-TEG system. Results of GEPSO reveal 
the promising improvement in terms of tracking compared to CS, PSO, P \& O and INC techniques. Just like the standalone PV module, GEPSO also successfully tracks the MPP in a short time, resulting in the fast reaching of the maximum level of the output power. The system's output oscillated more in the conventional $\mathrm{P} \& \mathrm{O}$ technique of MPPT, whereas INC slowly tracked power and reached the MPPT within $1.43 \mathrm{~s}$. INC also involves fluctuations during tracking. PSO and CS randomly start searching the search space so that a lot of oscillations are involved at the start and reach the MPPT within $0.78 \mathrm{~s}$ and $0.87 \mathrm{~s}$, respectively. The proposed GEPSO algorithm achieves the MPPT in a short time with weaker fluctuations.

The tracking time of GEPSO is $0.34 \mathrm{~s}$. The average power calculated by GEPSO is $1013.2 \mathrm{~W}$, CS is $1013 \mathrm{~W}$, INC is $994.9 \mathrm{~W}$, PSO is $962.5 \mathrm{~W}$, and P \& O is $994 \mathrm{~W}$. The quick and precise tracking of MPPT results in the reduction of the power loss and the efficiency increase of the hybrid PV-TEG system.

\subsection{Case 6: Non-Uniform Temperature on TEG}

This case deals with the unequal distribution of temperature on TEGs due to non-uniform irradiance on PV modules. Figure 18 shows the PV curve consisting of multiple LM occurred at $535.7 \mathrm{~W}$ and $423.1 \mathrm{~W}$, whereas GM exists at 576 $\mathrm{W}$. The techniques such as $\mathrm{P} \& \mathrm{O}$ and INC are unable to track GM unless they are initialized close to GM and are trapped at LM, i.e. at $535.7 \mathrm{~W}$ and $423.1 \mathrm{~W}$. These techniques produce significant fluctuations during tracking, which cause an additional loss of power. The MPP tracking of CS, PSO, P \& O, INC and GEPSO is shown in Figure 19(a) and the duty cycle comparison of implemented methods are illustrated in Figure 19(b). CS start tracking GMPP at $1.13 \mathrm{~W}$ and obtained an average power of $549.3 \mathrm{~W}$, while PSO started tracking at $1.19 \mathrm{~s}$ and achieved an average power of $542.2 \mathrm{~W}$. GEPSO successfully escape the LM trap and started tracking GMPP at $0.33 \mathrm{~s}$. The settling time of GEPSO is about $0.69 \mathrm{~s}$ and achieved an average power of $553.8 \mathrm{~W}$ which shows robustness of implemented technique in terms of settling time and average power.
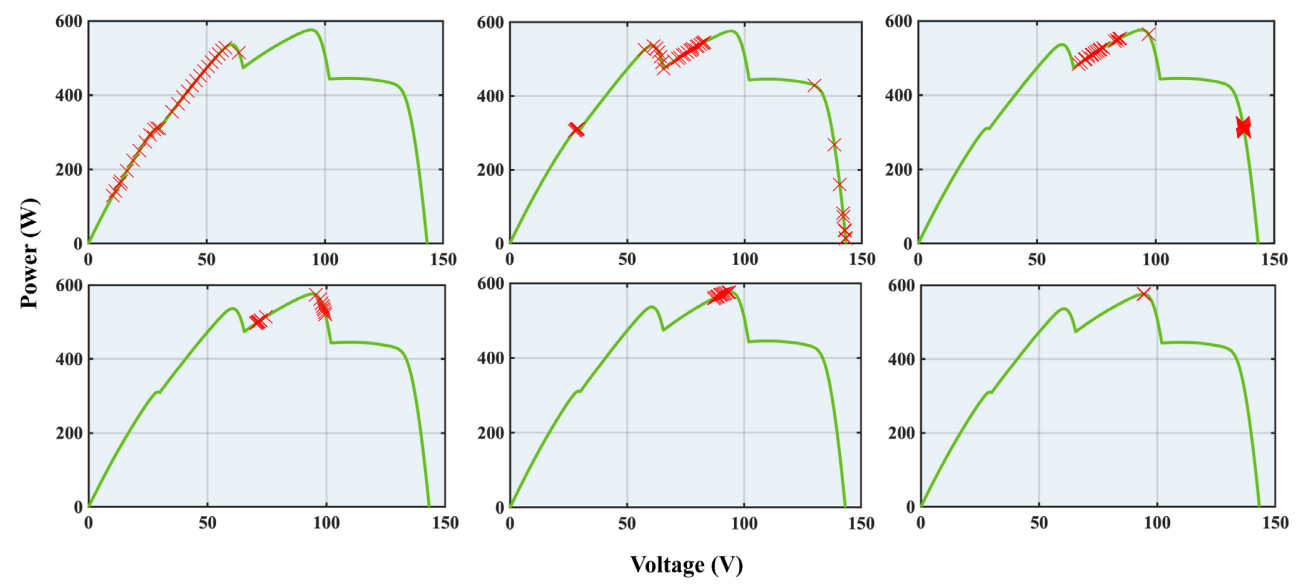

Figure 18. MPPT of Hybrid PV-TEG system in Case 6. 


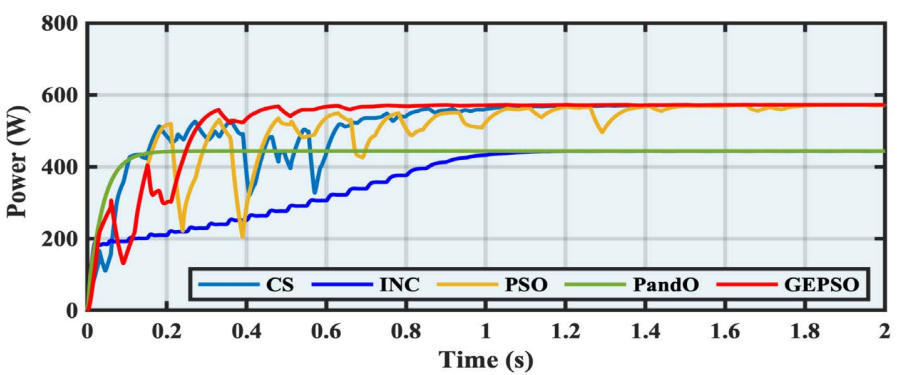

(a)

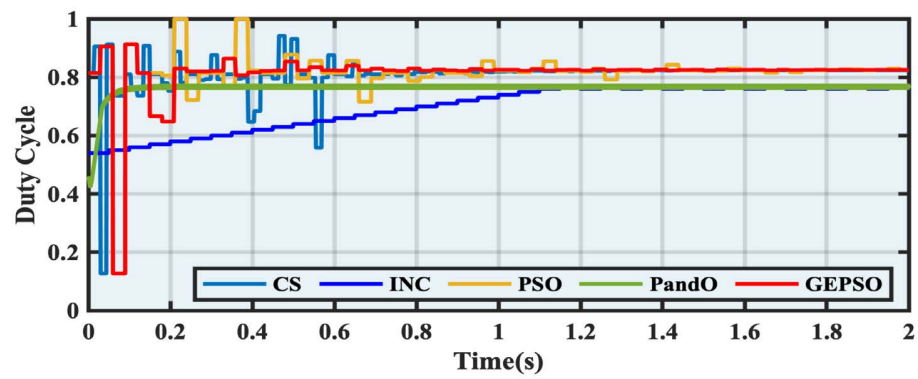

(b)

Figure 19. (a) Power comparison in Case 6 (b) Duty cycle comparison in Case 6.

\section{Conclusion}

This paper proposes a GEPSO based energy harvesting technique for PV and hybrid PV-TEG systems under various operating conditions. A comprehensive comparison is made with the standard MPPT techniques, including PSO, CS, and INC, respectively. The GEPSO technique is designed for strongly correlate search particles so that it can achieve quick convergence towards globally optimum solutions rapidly. In addition, the random velocity terms are introduced into the GEPSO technique and improvising the swarm exploration in unexplored regions of interest of the search space. Moreover, the comprehensive case studies validate the effectiveness and advantages of GEPSO for harvesting maximum energy. The outcomes demonstrated that GEPSO can outperform some state-of-the-art energy harvesting techniques, making the PV system generates more energy under different environmental conditions.

\section{Acknowledgements}

I would like to express my special thanks of gratitude to Professor Qiang Ling, who gave me the golden opportunity to do this wonderful research article, which helped me contribute to renewable energy.

\section{Conflicts of Interest}

The author declares no conflicts of interest regarding the publication of this paper.

\section{References}

[1] Babu, C. and Ponnambalam, P. (2018) The Theoretical Performance Evaluation of 
Hybrid PV-TEG System. Energy Conversion and Management, 173, 450-460. https://doi.org/10.1016/j.enconman.2018.07.104

[2] Attivissimo, F., Di Nisio, A., Lanzolla, A.M.L. and Paul, M. (2015) Feasibility of a Photovoltaic-Thermoelectric Generator: Performance Analysis and Simulation Results. IEEE Transactions on Instrumentation and Measurement, 64, 1158-1169.

[3] Hasanuzzaman, M., Malek, A.B.M.A., Islam, M.M., Pandey, A.K. and Rahim, N.A. (2016) Global Advancement of Cooling Technologies for PV Systems: A Review. Solar Energy, 137, 25-45. https://doi.org/10.1016/j.solener.2016.07.010

[4] Fathabadi, H. (2020) Novel Solar-Powered Photovoltaic/Thermoelectric Hybrid Power Source. Renewable Energy, 146, 426-434.

https://doi.org/10.1016/j.renene.2019.06.141

[5] Sahin, A.Z., Ismaila, K.G., Yilbas, B.S. and Al-Sharafi, A. (2020) A Review on the Performance of Photovoltaic/Thermoelectric Hybrid Generators. International Journal of Energy Research, 44, 3365-3394. https://doi.org/10.1002/er.5139

[6] Omer, G., Yavuz, A.H., Ahiska, R. and Calisal, K.E. (2020) Smart Thermoelectric Waste Heat Generator: Design, Simulation and Cost Analysis. Sustainable Energy Technologies and Assessments, 37, Article ID: 100623.

https://doi.org/10.1016/j.seta.2019.100623

[7] Meng, J.H., Zhang, X.X. and Wang, X.D. (2015) Characteristics Analysis and Parametric Study of a Thermoelectric Generator by Considering Variable Material Properties and Heat Losses. International Journal of Heat and Mass Transfer, 80, 227-235. https://doi.org/10.1016/j.ijheatmasstransfer.2014.09.023

[8] Hsiao, Y., Chang, W. and Chen, S. (2010) A Mathematic Model of Thermoelectric Module with Applications on Waste Heat Recovery from Automobile Engine. Energy, 35, 1447-1454. https://doi.org/10.1016/j.energy.2009.11.030

[9] Mcenaney, K., Kraemer, D., Ren, Z. and Chen, G. (2011) Modeling of Concentrating Solar Thermoelectric Generators. Journal of Applied Physics, 110, Article ID: 074502. https://doi.org/10.1063/1.3642988

[10] Kumar, S., Heister, S.D., Xu, X., Salvador, J.R. and Meisner, G.P. (2013) Thermoelectric Generators for Automotive Waste Heat Recovery Systems Part I: Numerical Modeling and Baseline Model Analysis. Journal of Electronic Materials, 42, 665-674. https://doi.org/10.1007/s11664-013-2471-9

[11] Kanagaraj, N., Rezk, H. and Gomaa, M.R. (2020) A Variable Fractional Order Fuzzy Logic Control Based MPPT Technique for Improving Energy Conversion Efficiency of Thermoelectric Power Generator. Energies, 13, Article No. 4531. https://doi.org/10.3390/en13174531

[12] Lin, J., Liao, T. and Lin, B. (2015) Performance Analysis and Load Matching of a Photovoltaic-Thermoelectric Hybrid System. Energy Conversion and Management, 105, 891-899. https://doi.org/10.1016/j.enconman.2015.08.054

[13] Mohd Shatar, N., Abdul Rahman, M.A., Muhtazaruddin, M.N., Shaikh Salim, S.A.Z., Singh, B., Muhammad-Sukki, F., Bani, N.A., Mohd Saudi, A.S. and Ardila-Rey, J.A. (2019) Performance Evaluation of Unconcentrated PhotovoltaicThermoelectric Generator Hybrid System under Tropical Climate. Sustainability, 11, Article No. 6192. https://doi.org/10.3390/su11226192

[14] Ibrahim, M.N., Rezk, H., Al-Dahifallah, M. and Sergeant, P. (2019) Hybrid Photovoltaic-Thermoelectric Generator Powered Synchronous Reluctance Motor for Pumping Applications. IEEE Access, 7, 146979-146988.

[15] Verma, V., Kane, A. and Singh, B. (2016) Complementary Performance Enhancement of PV Energy System through Thermoelectric Generation. Renewable and 
Sustainable Energy Reviews, 58, 1017-1026.

https://doi.org/10.1016/j.rser.2015.12.212

[16] Al-Shahri, O.A., Ismail, F.B., Hannan, M., Lipu, M.H., Al-Shetwi, A.Q., Begum, R. Al-Muhsen, N.F. and Soujeri, E. (2021) Solar Photovoltaic Energy Optimization Methods, Challenges and Issues: A Comprehensive Review. Journal of Cleaner Production, 284, Article ID: 125465. https://doi.org/10.1016/j.jclepro.2020.125465

[17] Motahhir, S., El Hammoumi, A. and El Ghzizal, A. (2018) Photovoltaic System with Quantitative Comparative between an Improved MPPT and Existing INC and P\&O Methods under Fast Varying of Solar Irradiation. Energy Reports, 4, 341-350. https://doi.org/10.1016/j.egyr.2018.04.003

[18] Zhu, W., Shang, L., Li, P. and Guo, H. (2018) Modified Hill Climbing MPPT Algorithm with Reduced Steady-State Oscillation and Improved Tracking Efficiency. The Journal of Engineering, 2018, 1878-1883. https://doi.org/10.1049/joe.2018.8337

[19] Islam, H., Mekhilef, S., Shah, N., Soon, T., Seyedmahmousian, M., Horan, B. and Stojcevski, A. (2018) Performance Evaluation of Maximum Power Point Tracking Approaches and Photovoltaic Systems. Energies, 11, Article No. 365.

https://doi.org/10.3390/en11020365

[20] El Khazane, J. and Tissir, E.H. (2018) Achievement of MPPT by Finite Time Convergence Sliding Mode Control for Photovoltaic Pumping System. Solar Energy, 166, 13-20. https://doi.org/10.1016/j.solener.2018.03.026

[21] Kesilmiş, Z., Karabacak, M.A. and Aksoy, M. (2020) A Novel MPPT Method Based on Inflection Voltages. Journal of Cleaner Production, 266, Article ID: 121473. https://doi.org/10.1016/j.jclepro.2020.121473

[22] Baimel, D., Tapuchi, S., Levron, Y. and Belikov, J. (2019) Improved Fractional Open Circuit Voltage MPPT Methods for PV Systems. Electronics, 8, Article No. 321. https://doi.org/10.3390/electronics8030321

[23] Hsu, T.W., Wu, H.H., Tsai, D.L. and Wei, C.L. (2019) Photovoltaic Energy Harvester with Fractional Open-Circuit Voltage Based Maximum Power Point Tracking Circuit. IEEE Transactions on Circuits and Systems II: Express Briefs, 66, 257-261. https://doi.org/10.1109/TCSII.2018.2838672

[24] Papaioannou, I.T. and Purvins, A. (2012) Mathematical and Graphical Approach for Maximum Power Point Modelling. Applied Energy, 91, 59-66. https://doi.org/10.1016/j.apenergy.2011.09.005

[25] Mohapatra, A., Nayak, B., Das, P. and Mohanty, K.B. (2017) A Review on MPPT Techniques of PV System under Partial Shading Condition. Renewable and Sustainable Energy Reviews, 80, 854-867. https://doi.org/10.1016/j.rser.2017.05.083

[26] Husain, M.A., Tariq, A., Hameed, S., Arif, M.S.B. and Jain, A. (2017) Comparative Assessment of Maximum Power Point Tracking Procedures for Photovoltaic Systems. Green Energy \& Environment, 2, 5-17.

https://doi.org/10.1016/j.gee.2016.11.001

[27] Mohamed, M.A., Zaki Diab, A.A. and Rezk, H. (2019) Partial Shading Mitigation of PV Systems via Different Meta-Heuristic Techniques. Renewable Energy, 130, 1159-1175. https://doi.org/10.1016/j.renene.2018.08.077

[28] González-Castaño, C., Restrepo, C., Kouro, S. and Rodriguez, J. (2021) MPPT Algorithm Based on Artificial Bee Colony for PV System. IEEE Access, 9, 43121-43133. https://doi.org/10.1109/ACCESS.2021.3066281

[29] Yang, B., Zhu, T., Wang, J., Shu, H., Yu, T., Zhang, X., Yao, W. and Sun, L. (2020) Comprehensive Overview of Maximum Power Point Tracking Algorithms of PV Systems under Partial Shading Condition. Journal of Cleaner Production, 268, Ar- 
ticle ID: 121983. https://doi.org/10.1016/j.jclepro.2020.121983

[30] Premkumar, M. and Sowmya, R. (2019) An Effective Maximum Power Point Tracker for Partially Shaded Solar Photovoltaic Systems. Energy Reports, 5, 1445-1462. https://doi.org/10.1016/j.egyr.2019.10.006

[31] Basha, C.H., Bansal, V., Rani, C., Brisilla, R.M. and Odofin, S. (2020) Development of Cuckoo Search MPPT Algorithm for Partially Shaded Solar PV SEPIC Converter. In: Das, K., Bansal, J., Deep, K., Nagar, A., Pathipooranam, P. and Naidu, R., Eds., Soft Computing for Problem Solving. Advances in Intelligent Systems and Computing, Springer, Singapore, 727-736. https://doi.org/10.1007/978-981-15-0035-0_59

[32] Soufi, M.B.Y. and Kahla, S. (2018) Particle Swarm Optimization Based Maximum Power Point Tracking Algorithm for Photovoltaic Energy Conversion System. 2018 15 th International Multi-Conference on Systems, Signals \& Devices (SSD), Yasmine Hammamet, 19-22 March 2018, 773-779. https://doi.org/10.1109/SSD.2018.8570633

[33] Zhang, X., Li, S., He, T., Yang, B., Yu, T., Li, H., Jiang, L. and Sun, L. (2019) Memetic Reinforcement Learning Based Maximum Power Point Tracking Design for PV Systems under Partial Shading Condition. Energy, 174, 1079-1090. https://doi.org/10.1016/j.energy.2019.03.053

[34] Parvaneh, M.H. and Khorasani, P.G. (2020) A New Hybrid Method Based on Fuzzy Logic for Maximum Power Point Tracking of Photovoltaic Systems. Energy Reports, 6, 1619-1632. https://doi.org/10.1016/j.egyr.2020.06.010

[35] Fathi, M. and Parian, J.A. (2021) Intelligent MPPT for Photovoltaic Panels Using a Novel Fuzzy Logic and Artificial Neural Networks Based on Evolutionary Algorithms. Energy Reports, 7, 1338-1348. https://doi.org/10.1016/j.egyr.2021.02.051

[36] Sedighizadeh, D., Masehian, E., Sedighizadeh, M. and Akbaripour, H. (2021) GEPSO: A New Generalized Particle Swarm Optimization Algorithm. Mathematics and Computers in Simulation, 179, 194-212.

[37] Mirza, A.F., Ling, Q., Javed, M.Y. and Mansoor, M. (2019) Novel MPPT Techniques for Photovoltaic Systems under Uniform Irradiance and Partial Shading. Solar Energy, 184, 628-648. https://doi.org/10.1016/j.solener.2019.04.034 